\title{
ANÁLISE DO PROGRAMA ENSINO INTEGRAL NA PERSPECTIVA DO DESEMPENHO ESCOLAR
}

\author{
ANALYSIS OF THE INTEGRAL EDUCATION PROGRAM \\ IN THE PERSPECTIVE OF SCHOOL PERFORMANCE
}

\begin{abstract}
ANÁLISIS DEL PROGRAMA DE EDUCACIÓN INTEGRAL EN LA PERSPECTIVA DEL RENDIMIENTO EDUCATIVO
\end{abstract}

\author{
Nonato Assis de Miranda ${ }^{\mathrm{I}}$ \\ EstéFANO VIZCONDE VERASZTOII \\ Ana Silvia Moço Aparício ${ }^{I}$
}

Resumo O objetivo precípuo deste artigo é analisar se a adesão de escolas ao Programa Ensino Integral (PEI), da Secretaria de Estado da Educação de São Paulo, na região do Grande ABC, repercute em melhoria do desempenho escolar. Considerando os resultados do Índice de Desenvolvimento da Educação São Paulo (Idesp) como um dos possíveis indicadores de desempenho escolar, este trabalho analisou o desempenho das escolas de três municípios do $\mathrm{ABC}$. Os resultados mostram que a dedicação exclusiva de docentes e gestores e o incremento financeiro nos salários tendem a refletir positivamente no avanço da atuação escolar, mas eles não podem ser generalizados porque nem todas as escolas obtiveram o mesmo êxito no programa. $\mathrm{O}$ artigo conclui que o aumento do tempo na escola por si só não garante processos de aprendizagem mais significativos, mas é uma alternativa para buscar a melhoria da qualidade social da educação desde que o modelo não priorize o mero estabelecimento de ranking entre as escolas integrantes do programa.

Palavras-chave: Ensino integral; Idesp; Programa Ensino Integral; Qualidade da eduCAÇÃO.

Abstract The main objective of this article is to analyze if the adherence of schools to the Integral Education Program (PEI) from the State Education Department of Sao Paulo, in the region of Great $\mathrm{ABC}$, has an impact on improving school performance. Considering

\footnotetext{
I Universidade Municipal de São Caetano do Sul (USCS), São Caetano do Sul/SP - Brasil

II Universidade Federal de São Carlos (UFSCar), Araras/SP - Brasil
} 
the results of the Sao Paulo Education Development Index (Idesp), as one of the possible indicators of school performance, this study analyzed the performance of schools in three $\mathrm{ABC}$ cities. The results show that the exclusive dedication of teachers and managers and the financial increase in wages tend to reflect positively in improving school performance, but they cannot be generalized because not all schools succeed in the program. The article concludes that the simple increase of the time in the school does not guarantee more significant learning processes, but it is an alternative for the search of the improvement of the social education quality, since it does not prioritize the simple establishment of among schools integrating the program.

Key-words: Integral education; Idesp; Integral Education Program; QualtTy of EdUCATION.

Resumen El objetivo principal de este artículo es analizar si la entrada de las escuelas en el Programa de Educación Integral (PEI), del Departamento de Educación del Estado de Sao Paulo, en la región del Gran $\mathrm{ABC}$, ha reflejado en un mejor rendimiento escolar. Teniendo en cuenta los resultados del Índice de Desarrollo de la Educación del Estado de Sao Paulo (Idesp) como posibles indicadores de rendimiento escolar, este estudio analizó el desempeño de las escuelas en tres municipios de la región $\mathrm{ABC}$. Los resultados muestran que la dedicación exclusiva de los profesores y de los gestores, y el aumento de los salarios, tienden a reflejar positivamente en la mejora del rendimiento escolar, pero no se puede generalizar, porque no todas las escuelas tienen éxito en el programa. El artículo concluye que el simple aumento del tiempo en la escuela no garantiza un aprendizaje más significativo, pero es una alternativa a la búsqueda de la mejora de la calidad social de la educación, de tal manera que no sólo priorice una sencilla clasificación entre las escuelas participantes en el programa.

Palabras clave: Educación integral; Idesp; Programa de Educación Integral; Calidad DE LA EDUCACIÓN.

\section{INTRODUÇÃo}

Este estudo faz parte do projeto de pesquisa intitulado "O Programa Ensino Integral da Rede Estadual de São Paulo: realizações, contradições e desafios" que, desde 2015, debruça-se, do ponto de vista dos princípios filosóficos, da política educacional e da formação de professores, na análise documental, nas bases de dados secundários da Secretaria de Estado da Educação de São Paulo (SEE) e empíricos coletados junto aos diferentes sujeitos (alunos, professores, professores coordenadores, gestores escolares e outros profissionais envolvidos) das escolas participantes do Programa Ensino Integral (PEI) com o intuito de avaliar o programa.

O PEI está inserido no Programa Educação - Compromisso de São Paulo instituído pelo Decreto Lei no 57.571 de 02 de dezembro de 2011 que, segundo a SEE, tem "[...] a finalidade de promover, amplamente, a educação de qualidade na rede pública estadual de ensino e a valorização de seus profissionais" (SÃO PAULO, 2011, s/p). 
Com base nesses princípios, a SEE definiu cinco pilares com foco na qualidade da educação paulista. São eles: Valorização do Capital Humano, Gestão Pedagógica, Educação Integral, Gestão Organizacional e Financeira, Mobilização da Sociedade que, em certa medida, estão interligados entre si, pois, ao investir em um deles, contribui-se para o desenvolvimento de outro.

Com a adoção do PEI, foi colocado à disposição da equipe gestora e grupo de professores um conjunto de ferramentas gerenciais em prol da obtenção dos resultados esperados, a partir de objetivos e premissas delineados pela SEE (LOPES; SERRA, 2014). Para tanto, a SEE, pensando nos propósitos do programa, definiu que uma das exigências aos selecionados para atuar no PEI é a adesão ao Regime de Dedicação Plena e Integral (RDPI), entendido como prestação de 40 horas semanais de trabalho. Dessa forma, fica proibido o desempenho, por parte dos educadores do PEI, de qualquer atividade remunerada, pública ou privada, durante o horário de funcionamento da unidade escolar (SÃO PAULO, 2013).

O pressuposto dessa política é que a dedicação exclusiva de gestores e professores, o aumento do tempo de estudo e a oferta de um currículo diversificado ao aluno deverão refletir positivamente tanto na melhoria da aprendizagem quanto na melhoria dos resultados educacionais que, no caso de São Paulo, se concretizam pelo Índice de Desenvolvimento da Educação São Paulo (Idesp).

Assim, tendo como objeto de análise os resultados do Idesp obtidos pelas escolas participantes do PEI, na região do Grande $\mathrm{ABC}$, busca-se, com este trabalho, analisar a performance dessas escolas no período compreendido entre o ingresso delas ao programa e o ano de 2015. Em termos mais específicos, pretende-se verificar se o incremento financeiro dos profissionais da educação e a dedicação exclusiva deles ao programa refletem positivamente na melhoria dos resultados educacionais.

Parte-se do pressuposto de que a adesão ao PEI é uma tendência de política educacional que potencializa a qualidade da educação e "[...] ganha progressivamente a adesão do poder público bem como de diversos setores e organizações da sociedade civil" (CENPEC; FUNDAÇÃO ITAÚ SOCIAL; UNESCO, 2011, p. 9).

Para efeito didático, este artigo está organizado em cinco partes. Além desta introdução, empreendeu-se um breve levantamento bibliográfico com vistas a apresentar a trajetória da educação integral no país; em seguida, analisa-se a implantação do PEI no Estado de São Paulo, tendo como ponto de partida documentos oficiais da SEE e artigos que discutem o assunto. Na quarta parte, os resultados do Idesp das escolas participantes do PEI são analisados e, por fim, são feitas as considerações finais sobre o estudo.

\section{A educaÇão em tempo integral no Brasil}

A educação em tempo integral tem sido considerada uma possibilidade para o alargamento dos trabalhos culturais e sociais, permanecendo presente nas propostas das diversas correntes políticas desde de 1940 do século XX. Esse modelo de educação perpassou e foi difundido por diferentes orientações ideológicas que buscaram a qualidade na educação por distintos interesses (FIGUEIREDO, 2014). 
Segundo essa autora, as concepções autoritárias e elitistas buscavam, por meio da educação integral, a ampliação do controle social e da distribuição dos indivíduos hierarquizados na sociedade envolvendo Estado, família e religião, tendo sido anunciadas pelo Movimento Integralista Brasileiro.

Por sua vez, as correntes liberais objetivavam a reconstrução das bases sociais para o desenvolvimento democrático e tiveram como referencial teórico o pensamento de John Dewey, a partir do qual a educação é considerada um meio para a reconstrução da experiência, compreendendo que o homem se desenvolve e se forma na ação e no fazer-se, não pela aprendizagem formal (SCHMIDT, 2009; CAVALIERE, 2010; MAURÍCIO, 2014), pois para Dewey, “[...] a educação é vida, e não preparação para a vida” (SCHMIDT, 2009, p. 150).

Portanto, de modo mais efetivo, a história da educação integral, no Brasil, tem como marco pioneiro o movimento da Escola Nova, que ganhou notoriedade após a divulgação do Manifesto dos Pioneiros da Educação Nova, em 1932, a partir do qual defendia-se a universalização da escola pública, laica e gratuita (BRANCO, 2012; DUTRA, 2014).

Anísio Teixeira, nas décadas de 1940 e 1950, difundiu a ampliação da função social da escola e seu fortalecimento como instituição com enfoque na educação integral. Assim, ele, "[...] além de elaborar alguns de seus princípios conceituais e práticos, constrói escolas modelos para consolidação desta educação" (MOTA, 2006, p. 4).

Segundo Gonçalves (2006), as propostas de escola de tempo integral sugeridas por Anísio Teixeira e de outros educadores de sua geração, representaram, para os seus alunos, uma oportunidade para uma vida melhor. Essas escolas:

[...] constituíram (sic) a possibilidade de reapropriação de espaços de sociabilidade crescentemente sonegados às classes trabalhadoras pelas reformas urbanas que lhes empurravam para a periferia da cidade. Para muitos desses alunos, essas escolas foram a única abertura para uma vida melhor (NUNES, C., 2001, p. 12-13 apud GONÇALVES, 2006, p. 2).

Posteriormente, na década de 1980, Darcy Ribeiro deu sequência aos princípios defendidos por Anísio Teixeira, já que esses dois pesquisadores vislumbraram um país efetivamente educado e democrático.

Com base nesse modelo de educação, foram criados, nos anos 1980, os Centros Integrados de Educação Pública (CIEP) que deram continuidade aos projetos idealizados por Anísio Teixeira. Com essa nova organização de ensino, a escola deveria ter seis horas diárias de atividades e funções que ultrapassariam o ensino e a aprendizagem e precisaria ser direcionada às crianças de classes populares. Ou seja, além de um currículo variado, as crianças deveriam receber alimentação e cuidados básicos (CAVALIERE, 2009; BRANCO, 2012; MAURÍCIO, 2014).

Nessa mesma década, os governos de alguns Estados, objetivando uma nova dimensão para a escola pública, iniciaram a reorganização educacional de seus respectivos Estados (FERRETTI, VIANNA, SOUZA, 1991). 
Assim, além dos CIEP, no Rio de Janeiro, foram criados também, em Curitiba, Estado do Paraná, o Projeto de Educação Integrada em período integral, em São Paulo, o Programa de Formação Integral da Criança (PROFIC) e os Centros Integrados de Educação Municipal (CIEM) em Porto Alegre, no Rio Grande do Sul (FIGUEIREDO, 2014).

Na década de 1990, o então presidente Collor decidiu implantar, no país, a escola de tempo integral. Contudo, sua proposta não influenciou significativamente as ações educacionais por ter priorizado a construção dos Centros Ligados ao Apoio da Criança (CIAC), posteriormente, intitulados pelo Ministério da Educação (MEC) como Centros de Atenção Integral à Criança e ao Adolescente (CAIC) e não, necessariamente, centros de educação. Com isso, perdeu-se o caráter de tempo integral para atenção integral (DEMO, 1997).

Atualmente, a educação de tempo integral está contemplada na legislação brasileira, por meio da Lei de Diretrizes e Bases da Educação Nacional, a LDB nº. 9.394/1996 que, em seu artigo 34, prevê a perspectiva de Educação Integral em Tempo Integral considerando que, "[...] a jornada escolar no Ensino Fundamental incluirá pelo menos quatro horas de trabalho efetivo em sala de aula, sendo progressivamente ampliado o período de permanência na escola" (BRASIL, 1996, p. 18). Observa-se ainda no $§ 2^{\circ}$. do mesmo artigo, a orientação para que o ensino fundamental seja ministrado progressivamente em tempo integral, a critério dos sistemas de ensino.

Analisando-se o exposto, fica evidente que o tratamento dado pelo governo à educação integral diz respeito ao aumento do tempo escolar; daí a expressão escola de tempo integral em detrimento de educação integral que " [...] expressa a superação de uma visão que limita a tarefa escolar às disciplinas convencionais, mas expressa também uma metodologia organizacional, um modo de fazer essa ampliação das funções da escola" (CAVALIERE, 2014, p. 1.214).

É oportuno mencionar que, na primeira década deste século, o incremento financeiro atribuído a esse modelo de educação representou um diferencial para a implementação da educação de tempo integral. A promulgação da Lei $n^{0}$. 11.494 (BRASIL, 2007) que aprovou o Fundo de Manutenção e Desenvolvimento da Educação Básica e de Valorização dos Profissionais da Educação (Fundeb) foi fundamental para garantir a ampliação do número de matrículas na escola de tempo integral. Assim:

Desde a LDB, Lei n. 9.394 (BRASIL, 1996), que indicou a adoção do tempo integral para o Ensino Fundamental progressivamente, até a implantação do FUNDEB, Lei n. 11.494 (BRASIL, 2007), que prevê repasse de recursos acrescido de $25 \%$ para alunos da rede pública que permanecem sete horas diárias ou mais, o número de matrículas em tempo integral vem crescendo: os anos iniciais do Ensino Fundamental passaram de 4,01\%, em 2009, para 8,87\%, em 2012, ultrapassando um milhão de matrículas em 2011; os anos finais galgaram de 2,73\%, em 2009 para 5,97\%, em 2012. No conjunto do Ensino Fundamental, já estamos no limiar de dois milhões de matrículas em tempo integral. As matrículas municipais passaram de 59,3\%, em 2009, para 70,3\%, em 2012 (MAURÍCIO, 2014, p. 877). 
Observa-se, portanto, que apesar do tímido tratamento dado pela LDB 9.394/1996 à educação de tempo integral, bem como, pelo Plano Nacional de Educação de 2001 (BRASIL, 2001), cujas diretrizes apontavam para o aumento da jornada escolar como alternativa para atenuar as disparidades sociais e expandir, de acordo com a democracia, as oportunidades de aprendizagem, esses dados indicam que a educação em tempo integral começa a dar sinais de institucionalização no país. Ademais, o

Censo Escolar (INEP, 2014) atesta a significativa ampliação da oferta de matrículas consideradas de tempo integral no período de 2007-2013, pois, atualmente, $34,7 \%$ das escolas públicas já oferecem matrículas em tempo integral e 13,2\% dos estudantes acessam essas matrículas (MOLL, 2014, p. 374).

Por fim, é salutar fazer referência à promulgação da Lei $n^{\circ}$. 13.005/2014, que aprova o Plano Nacional de Educação (2014-2024). Nesse dispositivo legal, a educação de tempo integral está contemplada na meta seis que almeja "[...] oferecer educação em tempo integral em, no mínimo, 50\% das escolas públicas, de forma a atender, pelo menos, 25\% dos (as) alunos (as) da educação básica" (BRASIL, 2014, p. 59). Ou seja, trata-se de uma meta muito mais ousada do que até então se propôs para a educação em tempo integral, cujo cumprimento, na íntegra, realizar-se-á somente daqui a alguns anos.

\section{O Programa Ensino Integral do Estado de São Paulo}

O tema da educação integral não é novo e, mesmo assim, tem ganhado, cada vez mais destaque no país já que, embora essa discussão remeta aos ideais de educação democrática da primeira metade do século XX, é a partir da década de 1990 que ele ganha outra dimensão e caráter, refletidos na Lei de Diretrizes e Bases da Educação (LDB 9.394/96). A partir de então, passa-se a “[...] vivenciar um contexto político e social favorável ao debate da educação integral com demonstrações explícitas a favor da agenda e da implementação de políticas de educação integral em tempo integral ou educação integral em jornada ampliada" (MOLL, 2011, p. 11) nos termos do Artigo 34 da LDB 9.394/1996.

Na primeira década deste século, o tema foi pauta da Conferência Nacional de Educação (abril de 2010) e esteve presente nos debates de diferentes atores institucionais da vida pública brasileira. Como resultado, a educação integral foi contemplada na meta seis do Plano Nacional de Educação 2014-2024.

Nesse contexto, a Secretaria da Educação de São Paulo (SEE) implantou, em 2012, o Programa Ensino Integral (PEI). Contudo, o PEI não foi criado a partir de um diagnóstico da realidade do ensino na escola pública paulista e, nem tampouco, está balizado por uma fundamentação técnico-pedagógica suficiente e articulada com o Projeto Escola de Tempo Integral (ETI) instituído pela Resolução SE 89, de 09 de dezembro de 2005. Contudo, a SEE reconhece que a ETI "[...] foi um passo significativo na consolidação dos princípios que sustentam sua política educacional, em direção à educação integral dos seus alunos" (SÃO PAULO, 2012b, p. 10). 
Ao contrário, o PEI foi inspirado em um projeto do Instituto de Corresponsabilidade pela Educação (ICE) e pela equipe de trabalho do Programa de Desenvolvimento dos Centros de Ensino Experimental de Ensino Médio (Procentro) que foram os responsáveis pela implantação do primeiro Centro de Ensino em Tempo Integral, no Estado de Pernambuco, no ano de 2004.

Em termos mais abrangentes:

[...] o Programa Ensino Integral foi concebido levando-se em consideração as demandas decorrentes de pesquisas, avaliações, bem como resultado de experiências educacionais atualmente desenvolvidas no Brasil e em diferentes países. A partir de estudos iniciais foram identificadas as condições de sucesso dessas experiências e as adaptações necessárias foram incorporadas ao modelo (SÃO PAULO, 2012b, p. 11).

Para adequar-se à realidade paulista, o projeto original sofreu uma série de adaptações para que pudesse atender às demandas dessa rede de ensino que são bem distintas da pernambucana. Contudo, aos poucos, o PEI foi construindo sua própria identidade o que permite afirmar que, atualmente, é um programa voltado às escolas da SEE do Estado de São Paulo que conta com um conjunto de ferramentas que subsidiam no monitoramento dos resultados educacionais.

O projeto original foi criado com base nas orientações da Organização das Nações Unidas (ONU) para a Educação, a Ciência e a Cultura (UNESCO), tendo como ponto de partida o Relatório Jacques Delors (SILVA; SILVA, 2016, p. 745). Segundo esses autores, em Pernambuco, o governo da época "[...] abriu mão da elaboração da concepção de educação integral, transferindo-a aos empresários".

Nesses termos:

[...] esta concepção articula-se no PEI à perspectiva de planejamento estratégico aplicado à área educacional, que tem como proposta realizar planejamento estratégico aplicado às escolas, com a obrigação destas em elaborar um Plano de Ação Educacional, 'espelhando-se nas concepções filosóficas da Tecnologia Empresarial Odebrecht (TEO) [...] e nos quatro pilares da Educação ou aprendizagens fundamentais contidas no relatório de Jacques Delors' (DUTRA, 2014, p. 25 apud SILVA; SILVA, 2016, p. 745-746).

Diante do exposto, nota-se que, para esses autores, o emprego do planejamento estratégico como ferramenta de gestão representa, pelo menos em parte, uma interferência da iniciativa privada na educação pública. Quando se analisa as concepções filosóficas da TEO, percebe-se que há sentido nessa afirmação, mas ela não pode ser radicalizada por entender que o emprego do planejamento estratégico pode subsidiar a gestão da escola.

O planejamento estratégico constitui-se como uma função gerencial relevante, a partir da qual a instituição se projeta para o futuro, delineando uma programação na qual os objetivos são definidos, estratégias são estabelecidas e recursos são alocados, visando à manutenção das organizações no mercado (MAXIMINIANO, 1995). 
Não obstante, é sabido que, no cotidiano das escolas, o processo de planejar estrategicamente ainda é "“[...] um desafio devido a distância entre sua elaboração e sua implementação, pois existe, inclusive, uma letargia conceitual sobre o tema" (CASTRO et al., 2015, p. 196). Sabe-se, também que, em virtude do excesso de demandas, a maioria dos gestores acaba deixando de lado o planejamento estratégico e adotando planos de ação imediatos. Assim:

[...] o resultado disso tem sido uma sequencia de tentativas frustradas, que retardam a eficiência e eficácia organizacional, tais como: copiar a estratégia do concorrente, ir por um caminho que todos estão indo, consultorias intermináveis, decisões erradas etc. (CASTRO et al., 2015, p. 196).

Em contrapartida, o PEI prevê a parceria com uma organização da sociedade civil que, em geral, dá um suporte de formação ao gestor para que ele possa apropriar-se do planejamento estratégico em sua prática de gestão evitando, portanto, essa sequência de tentativas frustradas. Destaca-se que "[...] eles recebem formação inicial e continuada sobre as metodologias inovadoras do Programa e passam por avaliação de desempenho todos os anos" (FODRA, 2016, p. 118).

Embora haja críticas às parcerias (SILVA; SILVA, 2016), é sabido que há experiências a esse respeito que, além de não desresponsabilizar o poder público, definem uma divisão de responsabilidades em prol de causas sociais, cujos resultados têm sido bastante satisfatórios (MOLL, 2011).

Essa autora analisou quatro experiências distintas no seu modus operandi e nas suas proposições metodológicas e, a partir desses estudos, constatou que as relações recíprocas e responsabilidades específicas do poder público e das organizações sociais podem representar a garantia da construção de uma "escola honesta"1 já que, nesses projetos, ficou evidente que houve:

[...] uma clara distinção, no que se refere a financiamento e sustentabilidade entre as experiências realizadas no âmbito das secretarias municipais de Educação e no âmbito das organizações da sociedade civil; nas primeiras buscam-se formas de financiamento permanente e com recursos próprios dos municípios, dos estados ou da União (MOLL, 2011, p. 14).

Nesses termos, a existência de parcerias entre governo e sociedade civil nem sempre representa a transferência de responsabilidade de serviços essenciais como a educação para a iniciativa privada. Ademais, sabe-se que essas parcerias têm sido muito almejadas na atualidade, já que representam ganhos bilaterais, pois quando ocorre a:

[...] assunção pelo poder público de suas responsabilidades e obrigações constitucionais, é desejável e necessário que se estabeleçam diálogos com as 'forças vivas da sociedade' - nas palavras do Manifesto dos Pioneiros da Educação

1 Essa expressão é utilizada por Darcy Ribeiro ao referir-se à escola para as classes populares em sua obra Testemunho. Rio de Janeiro: Apicuri; Brasília: UnB, 2009. 
Nova de 1932 -, que podem colaborar para a qualificação da tarefa de introduzir as novas gerações no conjunto de saberes, valores e possibilidades produzidos pela civilização da qual fazem parte (MOLL, 2011, p. 14).

Não obstante, essa mesma autora adverte que "[...] há que se ter muita clareza acerca do papel indutor e financiador do Estado, nas distintas esferas administrativas, para que de fato se possa construir a agenda da educação integral no Brasil como ação permanente" (MOLL, 2011, p. 14) e não como projeto transitório.

Diante do exposto, o PEI, na perspectiva do programa Educação - Compromisso de São Paulo e do projeto inicial (JACQUES DELORS e TEO), é um dos cinco pilares do programa citado e carro-chefe do discurso governamental segundo o qual, por meio do PEI, lançaram-se as bases de um novo modelo de escola e de um regime mais atrativo para a carreira do magistério (LOPES; SERRA, 2014). O raciocínio do então Secretário da Educação de São Paulo, Herman Jacobus Cornelis Voorwald, é que "[...] se não houver um trabalho rápido de recuperação da carreira, não teremos melhora na qualidade de educação" (COSTA, 2011, p. 1) e, para tanto, afirmou, à época, que a valorização do professor teria prioridade em sua gestão.

Supõe-se que esse discurso esteja atrelado ao pagamento de professores e gestores do PEI de uma gratificação de $75 \%$ sobre o salário base pela dedicação ao trabalho integral. Contudo, sabe-se que a permanência das designações desses profissionais no programa está condicionada à aprovação deles em avaliações de desempenho, periódicas e específicas, das atribuições desenvolvidas nas escolas, estabelecidas pela Lei Complementar $\mathrm{n}^{\circ}$. 1.164/2012, alterada pela LC nº. 1.191/2012 (SÃO PAULO, 2012a). Portanto, a despeito da importância dessa política, não há como afirmar que seja uma ação efetiva de resgate da carreira, pois não contempla todos os profissionais da rede.

O PEI tem como princípio a concepção de educação interdimensional (COSTA, 2008) e pressupõe o exercício da cidadania e protagonismo juvenil, compreendendo ações educativas sistemáticas voltadas para as quatro dimensões do ser humano: racionalidade, afetividade, corporeidade e espiritualidade.

Assim, ao adotar o PEI em sua rede, a SEE considera que "[...] as ações de educação na sociedade contemporânea devam ser asseguradas, tanto na perspectiva quantitativa (educação para todos) quanto na referência qualitativa (desenvolvimento de todas as dimensões de formação do educando)" (SÃO PAULO, 2012b, p. 10).

Com base no exposto se, por um lado, sabe-se que há críticas em relação ao PEI, por outro, sabe-se, também, que esse programa vem cumprindo o compromisso assumido pela SEE em relação à oferta de vagas tendo em vista que, desde sua implantação, tem apresentado um crescimento exponencial no que tange à quantidade de escolas participantes e, consequentemente, ao número de alunos atendidos.

Para ilustrar o exposto, constatou-se que, no ano de 2012, aderiram ao Programa 16 escolas de 11 diretorias que atendiam a cinco mil alunos. Em 2013, a adesão foi ampliada para 69 escolas de 38 diretorias, contemplando 17 mil alunos. Em 2014, o programa passou a atender 182 escolas de 64 diretorias e 55 mil alunos; no ano de 2015, o PEI alcançou 257 
escolas de 74 diretorias de ensino distintas distribuídas em todo o Estado (SÃO PAULO, 2015a), onde frequentam cerca de 80 mil alunos do Ensino Fundamental e Médio.

É oportuno lembrar que a adesão da escola ao programa é espontânea e não uma decisão da SEE. Para tanto, a cada ano há um período de inscrição quando as escolas interessadas em aderir ao PEI passam por uma pré-seleção conduzida pelas Diretorias de Ensino nas quais estão jurisdicionadas. Não obstante, antes desse processo a SEE faz um estudo minucioso das demandas por vaga na região, considerando a possibilidade de atendimento das famílias e professores que optarem pela não adesão ao PEI. Feito isso, se as condições forem favoráveis, a escola deverá submeter sua candidatura ao PEI ao Conselho de Escola que deliberará sobre o ingresso ou não dela no programa (SÃO PAULO, s.d).

Na perspectiva da organização e gestão, o PEI prevê dois modelos orientadores: o pedagógico e o de gestão com suas respectivas metodologias que têm um único objetivo: a busca pela "[...] qualidade social para uma educação que esteja além da construção unilateral dos conhecimentos e da aprendizagem dos conteúdos” (DUTRA, 2014, p. 25).

Considerando-se que uma educação com qualidade social, como sugere Dourado (2007, p. 923) é entendida "[...] como processo amplo de socialização da cultura, historicamente produzida pelo homem, e a escola, como locus privilegiado de produção e apropriação do saber, cujas políticas, gestão e processos se organizam, coletivamente ou não, em prol de objetivos de formação", o PEI, dadas as suas características, tem um arranjo curricular e uma proposta de ensino que vai ao encontro da qualidade social da educação.

Entre suas práticas, merece destaque o projeto de vida que transcende a formação cognitiva do aluno e considera a educação "[...] como prática social, portanto, constitutiva e constituinte das relações sociais mais amplas, a partir de embates e processos em disputa que traduzem distintas concepções de homem, mundo e sociedade" (DOURADO, 2007, p. 923) buscando, portanto, uma maior aproximação entre a vida escolar e o mundo do trabalho.

Essa perspectiva é favorecida pelo documento norteador do Modelo Pedagógico do PEI cujos princípios educativos fundamentais (a Educação Interdimensional, a Pedagogia da Presença, os quatro Pilares da Educação para o Século XXI e o Protagonismo Juvenil) ${ }^{2}$ eleitos para orientar a constituição de suas metodologias ajudam na procura da qualidade social da educação tendo como referência a busca pela formação de um jovem autônomo, solidário e competente.

Considerando-se que a educação integral não se resume apenas na ampliação do tempo de permanência do estudante na escola, o PEI delega à escola a responsabilidade de garantir ao aluno, no processo de operacionalização do modelo pedagógico, um currículo que:

[...] considera o sujeito em sua condição multidimensional, não apenas na sua dimensão cognitiva, como também na compreensão de um sujeito que é sujeito corpóreo, tem afetos e está inserido num contexto de relações. Isso vale dizer a compreensão de um sujeito que deve ser considerado em sua dimensão biopsicossocial (GONÇALVES, 2006, p. 3).

2 Para saber mais sobre esses princípios consulte as Diretrizes do PEI disponíveis em: $<$ http://www.educacao. sp.gov.br/a2sitebox/arquivos/documentos/342.pdf>. Acesso em: 13 nov. 2016. 
Para tanto, o currículo é integralizado e diversificado e tem uma matriz flexível, garantindo aulas e atividades com a participação contínua de estudantes, professores e equipe gestora em todos os espaços e tempos da escola (SÃO PAULO, 2012b, p. 13).

Por sua vez, o modelo de Gestão do PEI apresenta premissas que, ao se integrarem aos princípios educativos do Modelo Pedagógico, articulam as ações educativas desenvolvidas na escola. Seus instrumentos de gestão permitem acompanhar e monitorar o trabalho pedagógico e formular planos de formação continuada para a equipe escolar. Isto é, a escola, diante de suas finalidades educacionais, organiza-se numa gestão integrada de seus diferentes segmentos e contributos de todos, seja individual ou coletivamente. Dessa forma, “[...] o PEI articula a Educação Interdimensional (e as ênfases dadas ao Protagonismo Juvenil e ao Empreendedorismo) à perspectiva do planejamento estratégico da TEO" (SILVA; SILVA, 2016, p. 746).

No PEI, o modelo de gestão escolhido para as Escolas Estaduais de Ensino Fundamental e Médio é denominado de Tecnologia de Gestão Educacional (TGE), cuja finalidade é obter uma gestão eficaz, na expectativa de que os objetivos estabelecidos sejam alcançados (LOPES; SERRA, 2014).

Dada a simetria entre os dois modelos, a gestão pedagógica, ao estabelecer os acordos quanto aos resultados pretendidos e as suas estratégias, permite, após a análise de indicadores, a correção dos caminhos perseguidos para a qualidade do processo de ensino e de aprendizagem (SÃO PAULO, 2012b).

\section{Método}

Esta pesquisa classifica-se como um levantamento descritivo, bibliográfico e quantitativo. Conforme Sampieri, Collado e Lúcio (1998), um estudo descritivo é aquele que se preocupa em medir e expor como um fenômeno se manifesta em determinadas situações ou eventos. Destarte, esta pesquisa caracteriza-se como descritiva porque identifica os resultados do Idesp de escolas integrantes do PEI na região do ABC e analisa se a adesão delas a esse programa reflete em melhoria da qualidade da educação tendo como ponto de partida o cumprimento de metas definidas pela SEE a partir do Idesp como parâmetro; bibliográfica porque faz uso de referenciais teóricos disponíveis em livros e artigos (GIL, 2006) para fundamentação teórica do estudo e quantitativa porque recorreu a dados numéricos (MALHOTRA, 2006) disponíveis em bancos de informações (Boletim da Escola).

\section{As escolas de ensino integral do Grande ABC}

A ampliação da jornada escolar está inserida como estratégia principal para viabilizar metodologias propondo-se a elevação dos indicadores qualitativos de aprendizagem dos estudantes. Desse modo:

[...] o tempo de dedicação dos profissionais segue como importante fator para que, nesse maior tempo para o ensino, os docentes e demais profissionais possam atender plenamente os alunos nas suas diferentes expectativas e dificulda- 
des na medida em que, com melhores condições de trabalho se amplia a presença educativa dos docentes e o desenvolvimento do conhecimento e habilidades dos alunos (SÃO PAULO, 2012b, p. 11).

Uma característica do PEI é a ação orientada com a finalidade de alavancar os resultados das avaliações internas e externas (SÃO PAULO, 2013). Nesse Programa, a gestão é voltada para o resultado escolar, considerando a melhoria do desempenho do aluno e a redução do abandono escolar. A avaliação é empregada como forma de monitoramento e responsabilização por resultados e a qualidade da educação é mensurada por meio de indicadores qualitativos.

Assim, com o intuito de mensurar o desempenho das Escolas do Grande $\mathrm{ABC}$ que aderiram ao PEI, tomou-se como base o Idesp que é um indicador de qualidade utilizado pela SEE para monitorar o currículo do Ensino Fundamental e Ensino Médio de sua rede.

$\mathrm{Na}$ avaliação de qualidade das escolas, feita pelo Idesp, consideram-se dois critérios complementares: o desempenho dos alunos nos exames do Sistema de Avaliação de Rendimento Escolar do Estado de São Paulo (Saresp) e o fluxo escolar. O Idesp tem o papel de dialogar com a escola, em que fornece um diagnóstico de sua qualidade, indica os pontos em que precisa melhorar e sinaliza sua evolução ano a ano (SÃO PAULO, 2015b).

Em todo o Estado de São Paulo, o PEI contemplou, até 2015, 257 escolas. Desse total de escolas, 15 estão localizadas no Grande ABC, nos municípios de Santo André, São Bernardo do Campo e São Caetano do Sul. Mauá e Ribeirão Pires participam do modelo Escolas de Tempo Integral criado, em 2006, pela mesma rede, mas por uma orientação diferente da do PEI, não fazem parte desta análise.

Por sua vez, as escolas das cidades de Rio Grande da Serra e Diadema não integram qualquer Programa de Escolas em Tempo Integral da rede Estadual, embora Diadema tenha adotado o ensino integral nas escolas de sua rede por meio do Programa do Governo Federal "Mais Educação". Por esse motivo, também ficaram fora deste estudo.

Os resultados obtidos, por meio da pesquisa, nos três municípios investigados, estão apresentados e discutidos a seguir.

\section{Santo André}

Santo André possui seis escolas participantes do PEI cujo ingresso no programa teve início variado de 2012 a 2015, conforme Tabela 1 apresentada a seguir.

A E.E. Jardim Riviera apresentou, de 2013 para 2014, um crescimento de 20,3\% e $21 \%$, de 2014 para 2015. Ou seja, observa-se uma progressão simétrica na melhoria dos resultados. Por sua vez, as Escolas Dr. Carlos Garcia e Papa Paulo VI, que ingressaram no PEI, no ano de 2015, obtiveram, respectivamente, um resultado no Idesp de $43,2 \%$ e $56 \%$, superior, portanto, ao ano anterior.

A E.E. Dr. Manoel Grandini Casquel apresentou um crescimento significativo de 2012 para 2013 (44\%), supondo-se, com isso, que o ingresso dela no PEI trouxe uma melhora significativa no indicador de qualidade (Idesp). Essa tendência de crescimento manteve-se em 2014 (28\%), mas não se confirmou em 2015 (a escola obteve um resultado no Idesp $6,5 \%$ inferior à meta projetada para esse ano). 
Tabela 1 - Resultados do Idesp das Escolas do Programa Ensino Integral - Santo André-SP.

\begin{tabular}{|c|c|c|c|c|c|c|c|c|c|c|}
\hline $\begin{array}{c}\text { Escolas do Programa Ensino Integral } \\
\text { Santo André }\end{array}$ & $\begin{array}{c}\text { Ingresso } \\
\text { no PEI }\end{array}$ & Nível de Ensino & $\begin{array}{l}\text { IDESF } \\
\text { REAL }\end{array}$ & 2012 & IDES & & IDESF & & $\begin{array}{l}\text { IDESF } \\
\text { REAL }\end{array}$ & \\
\hline E.E. Dr. Carlos Garcia & 2015 & Fundamental (Al) & 4,8 & 4,58 & 4,93 & 4,91 & 5,39 & 5,06 & 7,72 & 5,5 \\
\hline E.E. Profa ${ }^{a}$ Cristina Fittipaldi & 2014 & Fundamental (AF) & 2,28 & 2,58 & 2,08 & 2,42 & 2,46 & 2,25 & 3,12 & 2,64 \\
\hline E.E. Jardim Riviera & 2012 & Ensino Médio & - & - & 2,85 & - & 3,43 & 2,96 & 4,15 & 3,52 \\
\hline E.E. Dr. Manoel Grandini Casquel & 2013 & Fundamental (AF) & 1,7 & 1,82 & 2,45 & 1,84 & 3,14 & 2,62 & 3,1 & 3,3 \\
\hline E.E. Profo. Nagib Miguel Elchmer & 2014 & Fundamental (AF) & 3,02 & 3 & 2,65 & 3,15 & 3,51 & 2,82 & 3,64 & 3,66 \\
\hline E.E. Papa Paulo VI & 2015 & Ensino Médio & 3,14 & 2,78 & 2,87 & 2,68 & 2,8 & 2,98 & 4,37 & 3,09 \\
\hline
\end{tabular}

Fonte: Elaboração dos autores (2016).

Quanto à E.E. Prof. ${ }^{a}$ Cristina Fitipaldi, que ingressou no PEI em 2014, constatou-se que apresentou um crescimento de 18,2\% comparado ao ano anterior, e 26,8\% em 2015. Por fim, a E.E. Prof ${ }^{\circ}$. Nagib Miguel Elchmer cresceu 32,5\% no primeiro ano de programa, mas apenas 3,7\% em 2015 (abaixo da meta projetada pelo Idesp).

Grosso modo, com base nesses resultados, depreende-se que o PEI, em Santo André, está representando um diferencial de qualidade para essas escolas. Ademais, a política de responsabilização, a exemplo do que ocorre com o PEI, além das promessas dos políticos, pode trazer também "[...] benefícios para a aprendizagem e a progressão educacional dos alunos" (BROOKE, 2006, p. 379) e uma nova perspectiva para a educação integral (LOMONACO; SILVA, 2013).

\section{São Bernardo do Campo}

São Bernardo do Campo conta com sete escolas participando do PEI, sendo que a E.E. Prof ${ }^{\circ}$. Marco Antônio Prudente de Toledo ingressou no programa somente em 2016 estando, portanto, fora desta análise.

Das seis escolas objeto desta análise, duas ingressaram no programa em 2013, apresentando os seguintes resultados: a E.E. Lauro Gomes de Almeida, apesar de obter um crescimento de $46,5 \%$, no primeiro ano, não cumpriu a meta em 2014, mas se recuperou, em 2015, com um superávit de 4\% da meta projetada; a E.E. Rudge Ramos não cumpriu a meta em 2013, ao contrário, teve um decréscimo de 13,8\%, recuperando-se, em 2014 e 2015, com um superávit de $10,3 \%$ e $23,1 \%$, respectivamente.

Das quatro escolas ingressantes no PEI em 2014, apenas a E.E. Amadeu Olivério não cresceu no seu primeiro ano de programa; a E.E. Prof. ${ }^{a}$ Faustina Pinheiro Silva cresceu 15\%; a EE Jean Piaget, $25 \%$ e a E.E. Senador Robert Kennedy, 32,5\%, no Ensino Fundamental (anos finais), e 100\% no Ensino Médio (de 1,53 em 2013 para 3,06 em 2014), conforme pode ser constatado na Tabela 2.

Se, por um lado, esses resultados sinalizam que o PEI seja o responsável pela melhoria da qualidade do ensino nessas escolas, por outro, é preciso considerar, também, o trabalho das equipes escolares que, por vezes, pode se sobrepor às orientações das políticas de governo. Portanto, não se pode esquecer que "[...] o mérito cabe mais às individualidades, à dedicação dos integrantes da escola e não aos programas propriamente ditos" (FERREIRA, 2008 apud BERTOLDO, 2015, p. 158). 
Tabela 2 - Resultados do Idesp das Escolas do Programa Ensino Integral - São Bernardo do Campo-SP.

\begin{tabular}{|c|c|c|c|c|c|c|c|c|c|c|}
\hline \multirow{2}{*}{$\begin{array}{c}\text { Escolas do Programa Ensino Integral } \\
\text { São Bernardo do Campo }\end{array}$} & \multirow{2}{*}{$\begin{array}{l}\text { Ingresso } \\
\text { no PEI }\end{array}$} & \multirow{2}{*}{ Nível de Ensino } & \multicolumn{2}{|c|}{ IDESP 2012} & \multicolumn{2}{|c|}{ IDESP 2013} & \multicolumn{2}{|c|}{ IDESP 2014} & \multicolumn{2}{|c|}{ IDESP 2015} \\
\hline & & & REAL & META & REAL & META & REAL & META & REAL & META \\
\hline E.E. Prof ${ }^{\circ}$ Amadeu Olivério & 2014 & Ensino Médio & 3,02 & 2,39 & 2,74 & 3,1 & 3,67 & 2,86 & 4,04 & 3,75 \\
\hline E.E. Profa. Faustina Pinheiro Silva & 2014 & Fundamental (AF) & 3,69 & 3,64 & 2,87 & 3,08 & 3,3 & 3,03 & 3,36 & 3,46 \\
\hline E.E. Lauro Gomes de Almeida & 2013 & Fundamental (AF) & 2,5 & 2,53 & 3,71 & 2,64 & 3,52 & 3,84 & 3,82 & 3,67 \\
\hline E.E. Senador Robert Kennedy & 2014 & Fundamental (AF) & 2,78 & 3,53 & 2,53 & 2,91 & 3,35 & 2,7 & 3,97 & 3,5 \\
\hline
\end{tabular}

Fonte: Elaboração dos autores (2016).

No ano de 2015, das seis escolas pesquisadas em São Bernardo do Campo, a E.E. Prof. ${ }^{\text {a }}$ Faustina Pinheiro Silva e a E.E. Senador Robert Kennedy (nível médio) não alcançaram a meta projetada pela SEE. Depreende-se, portanto, que o ingresso no PEI não é garantia, pelo menos imediata, de melhoria dos resultados educacionais, mas nem por isso deixa de ser uma política que potencializa a qualidade da educação (MOLL, 2011).

\section{São Caetano do Sul}

São Caetano do Sul tem duas escolas participando do PEI, mas apenas uma delas

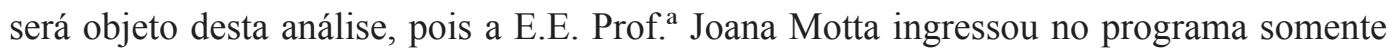
em 2016 não havendo, portanto, por ocasião da coleta de dados, resultados para efeito de comparação.

Analisando-se os dados da Tabela 3, observa-se que a EE Maria Trujilo Torloni, no Ensino Fundamental, não cumpriu a meta projetada para o primeiro ano de ingresso no PEI, mas se recuperou nos anos de 2014 e 2015 com um crescimento de 91\% e 9,93\%, respectivamente. Com relação ao Ensino Médio, a escola obteve resultado insatisfatório em 2013 e 2014, recuperando-se em 2015, com um crescimento de 28,6\%. Apesar do último resultado ser positivo, observa-se que ele está muito aquém da meta projetada para 2030 para esse nível de ensino que é 5 em uma escala de 0 a 10 (SÃO PAULO, 2015).

Não obstante, a análise desses resultados corrobora o seguinte ponto de vista:

[...] a ampliação da jornada escolar não visa somente elevar os índices de aprendizagem ou proporcionar proteção à infância e à adolescência. Essa questão traz também para o centro das discussões a função da educação oferecida pela escola, a importância de estudante ser conduzido por um educador especializado em outros momentos da jornada escolar, o que possibilitaria a ampliação das oportunidades de aprendizagem (LOMONACO; SILVA, 2013, p. 18). 
Tabela 3 - Resultados do Idesp das Escolas do Programa Ensino Integral - São Caetano do Sul-SP.

\begin{tabular}{|c|c|c|c|c|c|c|c|c|c|c|}
\hline \multirow{2}{*}{$\begin{array}{c}\text { Escolas do Programa Ensino Integral } \\
\text { São Caetano do Sul }\end{array}$} & \multirow{2}{*}{$\begin{array}{l}\text { Ingresso } \\
\text { no PEI }\end{array}$} & \multirow{2}{*}{ Nível de Ensino } & \multicolumn{2}{|c|}{ IDESP 2012} & \multicolumn{2}{|c|}{ IDESP 2013} & \multicolumn{2}{|c|}{ IDESP 2014} & \multicolumn{2}{|c|}{ IDESP 2015} \\
\hline & & & REAL & META & REAL & META & REAL & META & REAL & META \\
\hline \multirow{2}{*}{ E.E. Prof ${ }^{a}$ Joana Motta } & \multirow{2}{*}{2016} & Fundamental (AF) & 2,06 & 2,61 & 2,97 & 2,2 & 4,08 & 3,13 & 4,29 & 4,2 \\
\hline & & Ensino Médio & 2,41 & 2,11 & 2,69 & 2,51 & 2,06 & 2,81 & 2,65 & 2,2 \\
\hline E.E. Maria Trujilo Torloni & 2013 & Ensino Médio & 1,52 & 1,45 & 1,45 & 1,63 & 1,5 & 1,58 & 1,93 & 1,64 \\
\hline
\end{tabular}

Fonte: Elaboração dos autores (2016).

Por fim, é oportuno mencionar que São Caetano do Sul obteve, em 2014, o melhor resultado no Idesp entre os sete municípios do Grande $\mathrm{ABC}$ nos dois níveis de ensino, ou seja, ensino fundamental e médio (MIRANDA; APARÍCIO, 2015b).

\title{
CONSIDERaÇões FINAIS
}

Esta pesquisa foi realizada com o propósito de analisar o desempenho das escolas participantes no PEI na região do Grande ABC. Os resultados sinalizam que o ingresso das escolas nesse programa trouxe avanços para a melhoria dos indicadores educacionais, contudo, eles não podem ser generalizados por dois motivos: a) até o momento da realização desta pesquisa, o PEI não conta com uma metodologia de monitoramento testada para que se possa afirmar que esses resultados sejam tão-somente reflexos do ingresso da escola no programa; b) sabe-se que o esforço individual de gestores e professores, pode, por vezes, superar orientações de políticas centralizadas, portanto, não pode ser ignorado.

Depreende-se, portanto, que:

\begin{abstract}
O simples aumento do tempo na escola não garante processos de aprendizagem mais significativos, tampouco favorece o desenvolvimento de aspectos subjetivos e sociais dos indivíduos; assim, mais tempo em período escolar não quer dizer, necessariamente, mais aprendizagem, o que torna ainda mais importante a reflexão sobre as diferentes dimensões da educação integral (LOMONACO; SILVA, 2013, p. 18).
\end{abstract}

Por sua vez, não há como ignorar que a ampliação do tempo escolar que tem como foco a aprendizagem do aluno e não apenas o ensino, é uma ação necessária, mas não o suficiente para a busca da melhoria da qualidade social da educação que:

[...] exige medidas não só no campo do ingresso e da permanência, mas requer ações que possam reverter a situação da baixa qualidade da aprendizagem na educação básica, o que pressupõe, por um lado, identificar os condicionantes da política de gestão e, por outro lado, refletir sobre a construção de estratégias de mudança do quadro atual (DOURADO, 2007, p. 940).

Nesses termos, a ampliação da jornada escolar de parcial para integral pode subsidiar na melhoria da qualidade da educação porque “[...] na concepção de educação integral, a 
escola assume o papel de articuladora e gestora de espaços e tempos". Ademais, é nesse modelo de escola "[...] que os estudantes irão se deparar com novos desafios de aprendizagens e vivenciarão aspectos da socialização diferentes daqueles proporcionados por uma escola de turno parcial" (LOMONACO; SILVA, 2013, p. 20).

Isso ocorre porque a aprendizagem, nesse caso, transcende o espaço da sala de aula. Além disso, as escolas integrantes do PEI têm um currículo que, sem perder de referência a base nacional comum (BNC), prioriza a parte diversificada que é seu diferencial, pois tem foco no Projeto de Vida dos alunos como estratégia para dar sentido e significado ao papel da escola em sua formação e em suas escolhas futuras.

Não obstante, é oportuno dizer que "[...] a qualidade social na educação não se restringe a fórmulas matemáticas, tampouco a resultados estabelecidos a priori e a medidas lineares descontextualizadas" (SILVA, 2009, p. 223). Ao contrário, para que ela ocorra, é necessário que governos, gestores, professores e sociedade, em geral, entendam que:

[...] um olhar crítico direcionado para a trajetória da sociedade brasileira revela a distância entre as classes sociais, em decorrência de concepções políticas e medidas econômicas de privilégio para poucos e um processo de alargamento constante de exclusão social para a maioria. Foram séculos de omissão e de ocultamento das demandas da sociedade, sendo suas manifestações muitas vezes tratadas como caso de polícia e de desordem pública (SILVA, 2009, p. 223).

Sabe-se que programas como o PEI não dão conta dessas demandas por si só. Ao contrário, a resolução dos problemas educacionais só se concretizará “[...] com a clara determinação de se assumir a educação como prioridade maior, com a consequente vontade política de realizar as ações concretas em que se expressa essa prioridade" (SAVIANI, 2004, p. 124).

Por fim, é oportuno dizer que, embora a análise de desempenho das escolas participantes do $\mathrm{PEI}$, na região do $\mathrm{ABC}$, na perspectiva do Idesp, não apresente elementos concretos que articulem o incremento financeiro dos profissionais da educação e a dedicação exclusiva à melhoria dos resultados educacionais, supõe-se que essa ação, apesar de gerar sobrecarga de trabalho para a escola (gestores) e professores (BERTOLDO, 2015), favorece a melhoria da qualidade da educação nos termos das políticas educacionais da SEE.

\section{REFERÊNCIAS}

BERTOLDO, E. A escola em tempo integral: a face minimalista da política educacional brasileira. Práxis Educacional. Vitória da Conquista, v. 11, n. 20 p. 147-163 set./dez. 2015. Disponível em: <http://periodicos.uesb.br/index.php/praxis/article/viewFile/5278/5059>. Acesso em: 25 set. 2016.

BRANCO, V. Desafios para a implantação da Educação Integral: análise das experiências desenvolvidas na região sul do Brasil. Educ. rev. Curitiba, n. 45, p. 111-123, 
set. 2012. Disponível em <http://www.scielo.br/scielo.php?script=sci_arttext\&pid=S0104$-40602012000300008 \& \operatorname{lng}=\mathrm{pt} \& \mathrm{nrm}=\mathrm{iso}>$. Acessos em: 13 nov. 2016.

BRASIL. Lei $\mathbf{n}^{\mathbf{0}}$. 13.005, de 25 de junho de 2014 que aprova o Plano Nacional de Educação - PNE e dá outras providências. Disponível em: <http://www.planalto.gov.br/ccivil_03/_Ato2011-2014/2014/Lei/L13005.htm>. Acesso em: 15 ago. 2016.

. Lei no ${ }^{0}$ 11.494, de 20 de junho de 2007. Regulamenta o Fundo de Manutenção e Desenvolvimento da Educação Básica e de Valorização dos Profissionais da Educação FUNDEB. Diário Oficial da União. Brasília-DF, 22 jun. 2007.

. BRASIL. Plano Nacional de educação. Brasília-DF: MEC, Lei 10.172 de 9 de janeiro de 2001.

Lei 9.394 de 20 de dezembro de 1996. Estabelece as Diretrizes e Bases da Educação Nacional. Senado Federal: Brasília-DF, 1996.

BROOKE, N. O futuro das políticas de responsabilização educacional no Brasil. Cadernos de Pesquisa, v. 36, n. 128, p. 377-401, mai./ago. 2006. Disponível em: <http://www.scielo. br/pdf/cp/v36n128/v36n128a06>. Acesso em: 11 nov. 2016.

CASTRO, A. B. C. et al. O planejamento estratégico como ferramenta para a gestão escolar: um estudo de caso em uma instituição de ensino filantrópica da Bahia/BA. HOLOS, Ano 31, vol. 2, 2015, p. 195-211.

CAVALIERE, A. M. Escola de tempo integral versus alunos em tempo integral. Em Aberto, Brasília, v. 22, n. 80, p. 51-63, abr. 2009.

. Anísio Teixeira e a educação integral. Paidéia (Ribeirão Preto). Ribeirão Preto, v. 20, n. 46, p. 249-259, ago. 2010. Disponível em: <http://www.scielo.br/scielo.php?script $=$ sci_arttext\&pid=S0103-863X2010000200012\&lng=en\&nrm=iso $>$.

Acesso em: 12 nov. 2016.

. Escola pública de tempo integral no Brasil: filantropia ou política de estado? Educ. Soc. Campinas, v. 35, no ${ }^{\circ}$ 129, p. 1.205-1.222, out./dez. 2014. Disponível em: $<$ http://www. scielo.br/pdf/es/v35n129/0101-7330-es-35-129-01205.pdf>. Acesso em: 12 nov. 2016.

CENPEC; FUNDAÇÃO ITAÚ SOCIAL; UNICEF. A educação integral na agenda pública. In: Tendências para a educação integral. São Paulo: Fundação Itaú Social - CENPEC, 2011, p. 8-10.

COSTA, A. C. G. Educação: uma perspectiva para o século XXI. São Paulo: Canção Nova, 2008.

COSTA, M. M. Meta de SP é colocar magistério entre 10 carreiras mais desejadas. IG. São Paulo, 24 de maio de 2011, 17:57:01. Disponível em: <http://ultimosegundo. ig.com.br/educacao/meta-de-sp-e-colocar-magisterio-entre-10-carreiras-mais-desejadas/ n1596975981882.html>. Acesso em: 13 nov. 2016. 
DEMO, P. A nova LDB: ranços e avanços. Campinas, SP: Papirus, 1997.

DOURADO, L. F. Políticas e gestão da educação básica no Brasil: limites e perspectivas. Educação e Sociedade. Campinas, v. 28, n. 100 - Especial, p. 921-946, out. 2007. Disponível em: <http://www.scielo.br/pdf/es/v28n100/a1428100.pdf>. Acesso em: 13 nov. 2016.

DUTRA, P. Educação integral no Estado de Pernambuco: uma política pública para o ensino médio. Recife: Editora UFPE, 2014.

FERRETTI, J. C.; VIANNA, C. P.; SOUZA, D. T. Escola pública em tempo integral: o PROFIC na rede Estadual de São Paulo. Caderno de Pesquisas, São Paulo, n. 76, p. 5-17, fev. 1991.

FIGUEIREDO, J. S. B. A educação em tempo integral no contexto das políticas públicas brasileiras. In: CONGRESSO IBERO-AMERICANO DE POLÍTICA E ADMINISTRAÇÃO DA EDUCAÇÃO, 4, 2014. CONGRESSO LUSO BRASILEIRO DE POLÍTICA E ADMINISTRAÇÃO DA EDUCAÇÃO, 6, 2014. Porto, Portugal. Anais... 2014. Disponível em: <http://www.anpae.org.br/IBERO_AMERICANO_IV/GT5/GT5_Comunicacao/

JacquelineDeSousaBatistaFigueiredo_GT5_integral.pdf>.Acesso em: 1º out. 2016.

FODRA, S. M. Para uma educação inclusiva das minorias sexualmente distintas: a relevância da formação dos professores. Revista de Estudos Aplicados em Educação, v. 1, n. 1, jan./abr. 2016, p. 108-126.

GIL, A. C. Como elaborar projetos de pesquisa, 4. ed. São Paulo: Atlas, 2006.

GONÇALVES, A. S. Reflexões sobre educação integral e escola de tempo integral. Cadernos Cenpec n. 2, Educação Integral, 2º semestre 2006. Disponível em: <http://www. crmariocovas.sp.gov.br/pdf/es_tempointegral/Reflexoes_ed_integral.pdf?t=003 $>$ Acesso em: 10 nov. 2016.

LOMONACO, B. P.; SILVA, L. A. M. Percursos da educação integral em busca da qualidade e da equidade. São Paulo: CENPEC: Fundação Itaú Social - UNICEF, 2013.

LOPES, M. F. A.; SERRA, M. H. M. D. Escolas de tempo integral no estado de São Paulo: características e princípios que norteiam o programa de ensino integral. Imagens da Educação, v. 4, n. 3, p. 85-91, 2014.

MALHOTRA, Naresch K. Pesquisa de Marketing: uma orientação aplicada, 4. ed. Porto Alegre: Bookman, 2006.

MAURÍCIO, L. V. Ampliação da jornada escolar: configurações próprias para diferentes contextos - Brasil e Europa. Ensaio: avaliação Políticas Públicas em Educação. Rio de Janeiro, v. 22, n. 85, p. 875-898, out./dez. 2014. Disponível em: <http://www.scielo.br/pdf/ ensaio/v22n85/v22n85a02.pdf>. Acesso em: $1^{\mathrm{o}}$. nov. 2016.

MAXIMINIANO, Antonio C. A. Introdução à Administração, 4. ed. São Paulo: Atlas, 1995. 
MIRANDA, N. A.; APARÍCIO, A. S. M. Avaliação e gestão de resultados no Grande ABC. Anais do XII Congresso Nacional de Educação - Educere. PUCPR, 26 a 29/10/2015. Disponível em: <http://educere.bruc.com.br/anais/p1/trabalhos.html?q=nonato + assis + de + miranda>. Acesso em: 14 nov. 2016.

MOLL, J. Educação integral no Brasil: itinerários na construção de uma politica pública possível. In: Tendências para a educação integral. São Paulo: Fundação Itaú Social CENPEC, 2011, p. 11-17.

. O PNE e a educação integral: desafios da escola de tempo completo e formação integral. Retratos da Escola. Brasília, v. 8, n. 15, p. 369-381, jul./dez. 2014.

MOTA, S. M. C. Escola de tempo integral: da concepção à prática. In: SEMINÁRIO DA REDESTRAGO - Regulação Educacional e Trabalho Docente, 6, 2006. Rio de Janeiro. Anais... UERJ - Rio de Janeiro-RJ, 2006. Disponível em: <http://www.fae.ufmg.br/estrado/cd_viseminario/trabalhos/eixo_tematico_1/escola_de_tempo_int.pdf $>$. Acesso em: 2 out. $201 \overline{6}$.

SAMPIERI, R. H.; COLLADO, C. F.; LUCIO, P. B. Metodología de la investigación. México: McGraw-Hill, 1998.

SÃO PAULO. Decreto $\mathbf{n}^{\mathbf{0}}$. 57.271, de 2 de dezembro de 2011. Institui, junto à Secretaria da Educação, o Programa Educação - Compromisso de São Paulo e dá providências correlatas. Disponível em: <http://www.al.sp.gov.br/repositorio/legislacao/decreto/2011/ decreto-57571-02.12.2011.html>. Acesso em: 4 mai. 2016.

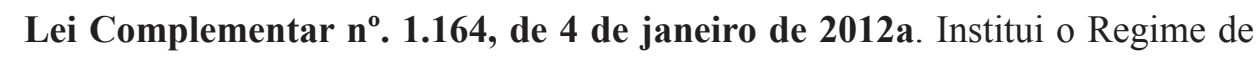
Dedicação Plena e Integral - RDPI e a Gratificação de Dedicação Plena e Integral - GDPI aos integrantes do Quadro do Magistério em exercício nas Escolas Estaduais de Ensino Médio de Período Integral, e dá providências correlatas. Disponível em: $<$ http://www.al.sp. gov.br/repositorio/legislacao/lei.complementar/2012/lei.complementar-1164-04.01.2012. html>. Acesso em: 5 out. 2016.

. Diretrizes do Programa Ensino Integral. São Paulo: SEE, 2012b. Disponível em: <http://www.educacao.sp.gov.br/a2sitebox/arquivos/documentos/342.pdf>. Acesso em: 5 out. 2016 .

. Decreto nº 59.354, de 15 de julho de 2013. Dispõe sobre o Programa Ensino Integral de que trata a Lei Complementar $n^{\circ}$. 1.164, de 4 de janeiro de 2012, alterada pela Lei Complementar $n^{\circ}$. 1.191, de 28 de dezembro de 2012. Disponível em: <http://www. al.sp.gov.br/repositorio/legislacao/decreto/2013/decreto-59354-15.07.2013.html>. Acesso em: 8 ago. 2016.

Ensino Integral: escolas participantes do programa (2012-2015). São Paulo: SEE, 2015a. Disponível em: <http:/www.educacao.sp.gov.br/a2sitebox/arquivos/documentos/918.pdf>. Acesso em: 15 abr. 2016.

. Programa de Qualidade da Escola. São Paulo: SEE, março 2015b. Disponível em: $<$ http://idesp.edunet.sp.gov.br/Arquivos/NotaTecnica2014.pdf > . Acesso em: 15 abr. 2016. 
Orientações para adesão ao programa ensino integral. São Paulo: SEE, s.d. Disponível em: <http://www.educacao.sp.gov.br/a2sitebox/arquivos/documentos/738. pdf $>$. Acesso em: 28 out. 2016.

. Resolução SE n⿳. 89, de 9 de dezembro de 2005. Dispõe sobre o Projeto Escola de Tempo Integral. Disponível em: <http://siau.edunet.sp.gov.br/ItemLise/arquivos/89_05. HTM?Time=10/14/2009\%203:39:14\%20PM>. Acesso em 10 nov. 2016.

SAVIANI, D. Por uma outra política educacional. In: SAVIANI, D. Da nova LDB ao novo Plano Nacional de Educação: por uma outra política educacional, 5. ed. Campinas: Autores Associados, 2004.

SCHMIDT, I. A. John Dewey e a Educação Para uma Sociedade Democrática. Contexto \& Educação, ano 24, n. 82, jul./dez. 2009, p. 135-254. Disponível em: <https://www.revistas.unijui.edu.br/index.php/contextoeducacao/article/viewFile/1016/772>. Acesso em: $1^{\circ}$. nov. 2016.

SILVA, K. N. P; SILVA, J. A. A. Política de Avaliação e Programa de Educação Integral no Ensino Médio da Rede Estadual de Pernambuco: os limites da centralidade da avaliação nas políticas educacionais. Práxis Educativa. Ponta Grossa, p. 736-756, v. 11, n. 3, set./dez. 2016. Disponível em: < http://www.revistas2.uepg.br/index.php/praxiseducativa>. Acesso em: 13 nov. 2016.

SILVA, M. A. Qualidade social da educação pública: algumas aproximações. Cad. Cedes. Campinas, vol. 29, n. 78, p. 216-226, mai./ago. 2009 Disponível em: <http://www.scielo. br/pdf/ccedes/v29n78/v29n78a05.pdf>. Acesso em: 22 abr. 2016.

\section{Dados dos Autores}

\section{Nonato Assis de Miranda}

Doutor em Educação pela Universidade Estadual de Campinas. Coordenador do Programa de Pós-Graduação em Educação da Universidade Municipal de São Caetano do Sul. São Caetano do Sul/SP - Brasil. mirandanonato@uscs.edu.br

\section{Estéfano Vizconde Veraszto}

Doutor em Educação, Ciência e Tecnologia pela Universidade Estadual de Campinas. Professor da Universidade Federal de São Carlos. Araras/SP - Brasil. estefanovv@gmail.com

\section{Ana Silvia Moço Aparício}

Doutora em Linguística Aplicada pela Universidade Estadual de Campinas. Vice Coordenadora do Programa de Pós-Graduação em Educação da Universidade Municipal de São Caetano do Sul. São Caetano do Sul/SP - Brasil. anaparicio@uol.com.br

Submetido em: 20-11-2016

Aceito em: 22-5-2017 